\title{
Concept of Circular Economy in Eco-Friendly Furniture Design
}

\author{
Dina Fekry Gamal \\ Associate Professor - Interior Design and Furniture Department - Faculty of Applied Arts - Helwan University \\ \begin{tabular}{l|l|l} 
Submit Date: 2021-10-15 12:02:48 & Revise Date:2021-11-01 07:29:51 & Accept Date: 2021-11-06 08:58:00
\end{tabular}
}

DOI: 10.21608/jdsaa.2021.101152.1140

KEYWORDS:

Circular economy; Recycle; Reuse; Zero Waste; Sustainable Design; ECO- Friendly Furniture Design.

\begin{abstract}
:
The world faces now a very critical issue by getting more pollution. This research is based on studying the meaning of circular economy, objectives and resources, green furniture, eco design and sustainability which is one of the recent global trends, depends on the spreading and use of the recycling culture of natural materials. Pointed out the importance of natural wood and its different types of waste and sources. It also explains the difference between recycling and reuse. And the advantages of reusing the waste wood again in the design of innovative pieces of furniture. The researcher designed a furniture unit from the remains of used wooden panels, as an example of reusing wood wastes and spreding of its many advantages.
\end{abstract}

\section{Search problem:}

- Not only, a lot of wood waste was not usefully used but also, resulted in serious pollution due to the method in which we get rid of it.

\section{Search objectives:}

- Reaching designs of furniture units that depends on use of wood waste to limit both consumption of natural material and pollution. cation of the proposed solutions, where the clear improvement appeared in all problems, the improvement of work environment, the lower cost for products and higher competitiveness for the facility 


\section{Introduction:}

Pollution is the process of making land, water, air or other parts of the environment dirty and not safe or suitable to use. This can be done through the introduction of poisons into a natural environment. One of the main environmental problems is air pollution, resulting from fossil fuels burning. In addition to water pollution which is caused by the breaking down of old and consumed water networks, as well as the various problems in building; designing and maintenance of sewage system.

Egypt is considered to be one of the most countries linked with increasing environmental problems. The Government of Egypt identifying and deals seriously with these problems. The Egyptian Ministry of Environment has initiated new policies that include risk minimization, law application and treatment of pollution at source, mitigation procedures and inter-sectorial cooperation. (1) It is estimated that 60 million tons of solid wastes are generated every year in Egypt. Honestly, Furniture manufacturing is one of the main sources of soiled pollutants. (2)

Nowadays, the whole world is moving towards pollution prevention, Fig. (1) (Sometimes referred to as source reduction) which is the using of materials, processes or practices that reduce or eliminate the creation of pollutants or wastes at the source. Pollution prevention includes practices that reduce the use of hazardous materials, energy, water or other resources and practices that protect natural resources through conservation or more efficient use. Pollution prevention should be considered the first step in a hierarchy of options for reducing the generation of pollution. The next step in the hierarchy is responsible recycling of any wastes that cannot be reduced or eliminated at the source. Wastes that cannot be recycled should be treated in accordance with environmental standards. Finally, any wastes that remain after treatment should be disposed of safely. (3)

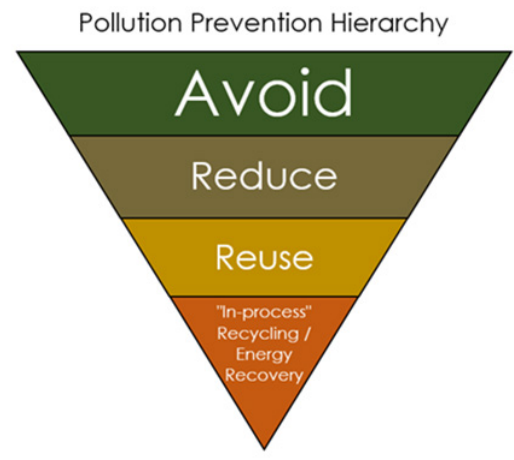

Fig. (1) Pollution prevention
Perhaps the best way to understand pollution prevention is to consider a few examples of some possible types of pollution prevention techniques and processes. Some general examples of pollution prevention techniques are described below:

1. Production Planning and Arrangement: plan and sequence production so that only necessary operations are performed and that no operation is needlessly "undone" by a following operation.

2. Process or equipment modification: change the Process, parameters or equipment used in that process, to reduce the amount of waste generated.

3. Raw material substitution or elimination: replace existing raw materials with other materials that produce less waste, or a nontoxic waste.

4. Loss prevention and housekeeping: perform preventive maintenance and manage equipment and materials so as to minimize opportunities for leaks, spills, evaporative losses and other releases of potentially toxic chemicals.

5. Waste segregation and separation: avoid mixing different types of wastes, and mixing hazardous wastes with non-hazardous wastes. This technique makes the recovery of hazardous wastes easier by minimizing the number of different hazardous constituents in any given waste stream. Also, it prevents the corruption of non-hazardous wastes.

6. Closed-loop Recycling: use or reuse of a waste as an ingredient or feedstock in the production process on-site. Recycling in which a waste is recovered and reused in the production process onsite as an input is a form of pollution prevention.

7. Training and Control : provide employees with the information and the motivation to minimize waste generation in their daily duties.

\section{1 - Circular economy:}

Circular Economy is an alternative strategy for traditional line of economy (make, use, dispose) Fig. (2 ) in which we keep resources in use for as long as possible, extract the maximum value from them in use, then recover and regenerate products and materials at the end of each service life.(4)

Another definition of circular economy could be: a model of production and consumption, which involves sharing, leasing, reusing, repairing, refurbishing and recycling existing materials and products as long as possible. In this way, the life cycle of products is prolonged. 
Although world's population is growing and so as the demand for raw materials. However, the supply of crucial raw materials is limited.

On the other hand some countries are dependent on other countries for their raw materials, in addition, extracting and using raw materials has a major impact on the environment. It also increases energy intake and $\mathrm{CO} 2$ emissions. However, a smarter use of raw materials can lower $\mathrm{CO} 2$ emissions .

\section{1-1 Benefits of circular economy:}

Moving towards a more circular economy could deliver benefits such as:

Reducing pressure on the environment, improving the security of supplying of raw materials, increasing competitiveness, stimulating innovation and creating jobs.

Rules such as waste prevention, Eco design and reuse could save companies money while also reducing total annual greenhouse gas emissions. Currently, the production of materials that we use every day, account for about $45 \%$ of the $\mathrm{CO} 2$ emissions. (5)

As a result, the world must work on achieving a balance between the benefits provided by technology and the damages it brings.

Every year, European Union produces more than 2.5 billion tons of waste. It is currently updating its legislation on waste management to promote a shift to a more sustainable model which is the circular economy.

In March 2020 the European Commission presented, under the European Green Deal and in line with a proposed new industrial strategy, the new circular economy action plan that includes proposals on more sustainable product design .

In practice, it implies reducing waste to a minimum. When a product reaches the end of its life, its materials are kept within the economy wherever possible.

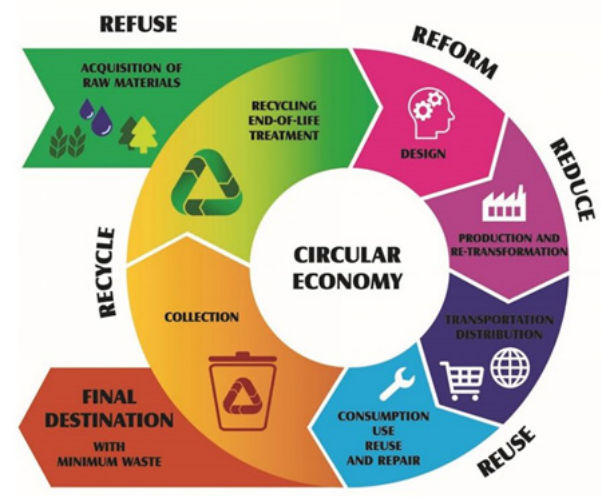

Fig. (2) Circular economy process

\section{1-2 Circular economy in Egypt:}

Egypt was among the six (grow countries) listed by the 2020 circularity gap report. The largest countries falling under the grow profile are China, Indonesia, Brazil, Mexico, Vietnams and Egypt. Egyptian minister of international cooperation said that these countries represent the only group of overall positive trade balance, accelerating transition to circular economy. She said, in Jane 2020 I shared with you the minister vision to strengthen engagement aimed at achieving a circular economy. Today I am proud that Egypt featured as grown country in the 2020 circular gap report.(6)

CAIRO-4 February 2021: The cabinet's Information and Decision Support Centre (IDSC) has published an info graphic on the continuity of Egypt's listing within the category of growth-stage countries in the Circular Gap Report 2021, along with five major emerging markets, namely China, Mexico, Indonesia, Vietnam and Brazil.

The report aims to direct the attention of decision-makers in economically developed countries towards the importance of take on circular economy strategies for a better future for all people.

The growth-stage countries in the report are considered promising economies that are likely to lead the transformation process into the circular economy. They are responsible for increasing the rates of resource recycling to ensure the success of significant strategies. (7)

\section{2-Sustainability:}

The most often cited definition for sustainability is "development that meets the needs of the present without cooperating the ability of future generations to meet their own needs". Sustainable design is the target to reduce or completely eliminate negative environmental impacts through thoughtful designs. This concept can be applied across all fields of design such as designing buildings or products. (8)

The overall goal of sustainable development (SD) is the long-term stability of the economy and environment; this is only achievable through the integration and acknowledgement of economic, environmental, and social concerns throughout the decision making process.

In addition to substitutability, this definition of sustainability is also founded on several other important principles. Contained within the common definition 
of sustainable development, intergenerational equity recognizes the long-term scale of sustainability in order to address the needs of future generations. (9)

\section{2-1-Sustainable Interior Design and furniture:}

Sustainable Interior Design can be combined through various techniques: such as: water efficiency, energy efficiency, using non-toxic, sustainable or recycled materials, using manufactured processes and producing products with more energy efficiency, building longer lasting and better functioning products, designing reusable and recyclable products, following the sustainable design standards and guidelines, and more. For example, a room with large windows to allow for maximum sunlight should have neutral color interiors to help bounce the light around and increase comfort levels while reducing light energy requirement.

Interior Designers must take types of paints, adhesives, and more into consideration during their designing and manufacturing phase so they do not subsidize to harmful environmental factors. Furthermore, incorporating sustainability can begin before the construction process begins. Purchasing items from sustainable local businesses, studying the long life of a product, taking part in recycling by purchasing recycled materials, and more should be taken into concern. Every environment and space can incorporate materials and choices to reducing environmental impact, while still providing durability and functionality. (8)

\section{2-2- Eco-friendly furniture:}

One way to avoid wood waste problems is to select green furniture pieces. "Investing in environmentally preferable furniture goes a long way toward creating a unified, durable, and productive environment," says John Michael, vice president and general manager of Business Interiors by Staples. "It helps companies meet sustainable goals, achieve relevant certifications and standards, save employee health, and segregate themselves from competitors." (10)

Manufacturers create sustainable furniture using materials that have a minimal negative impact on the environment. Sustainable furniture uses:

- Woods or other materials that come from renewable sources.

- Minimal chemicals that can pollute the environment.

- Local material and/or manufacturing to save on transportation.
Eco-friendly furniture causes less damage to the environment and makes your home environment safer. When you choose eco furniture made with minimal quantities of chemicals, you'll get less harmful pollutants. (11)
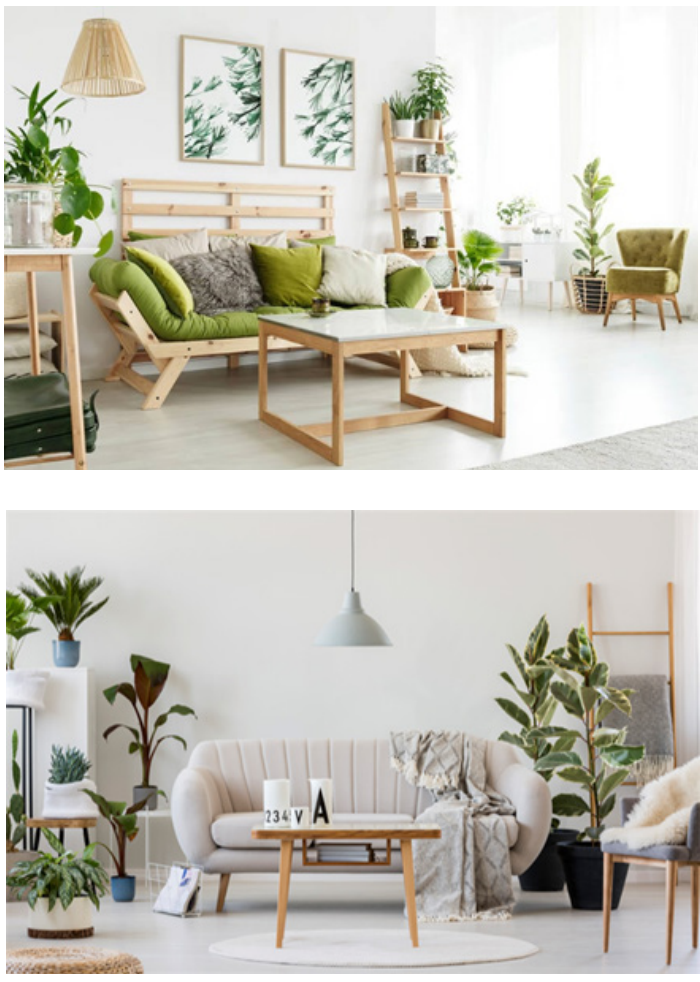

Fig. ( 3 ) Eco-friendly furniture causes less damage to the environment and makes your home environment safer

\section{2-3- Benefits of Eco-friendly furniture:}

Eco-friendly furniture is an unclear term that encompasses everything from low Volatile organic compounds (VOC) finishes and recycled content to lifecycle and durability considerations. Eco-friendly pieces may offer one or a combination of the following benefits:

- Recycled or recovered content (wood, plastics, metals).

- No- or low-VOC levels.

- Rapidly renewable or bio-based materials.

- Recyclability, including packaging.

- Environmentally preferable supply chain and manufacturing processes.

- Ability to be modified or reconfigured.

- Compatible with green and mild cleaning chemicals. 
- Durability and longevity.

- Easy replacement and serviceability of key parts.

\section{3-Waste Reduction:}

Nowadays, all communities are inspiriting residents to rethink what waste is and to aim toward the concept of (zero waste).

Waste reduction is the highest priority for solid waste management according to the soiled waste management and it is preferred over recycling and composting because the social environmental and an economic costs are typically lower for waste reduction .Importantly, efforts to reduce and reuse waste translate indirectly into cost savings as the disposal tonnage and associate costs are reduce. (12)

Lately, recycling considered as heart of waste disposal. Many disposal companies claim to recycle up to $95 \%$ or even $100 \%$ of what they collect. However, what most people refer to simply as 'recycling' involves a wide range of activities.

\section{3-1-Wood waste:}

Researches approve that wood material accounts for around $10 \%$ of all material deposited in landfills annually. (13)

Wood waste is a valuable resource that is plentifully available and can be used either for material recycling or energy production, depending on the quality grade. The term "waste wood" includes all woods and wood-based products that have come to the end of their product lifespan and therefore fall under the definition of waste.

Wood waste considered as a very important materials with different components such as shown in fig. (4) : particleboards, medium density fiberboards (MDF), ply-wood, oriented strand boards (OSB), and other wood composites which manifold applied in the production of furniture, paneling and roof covers, and other matters.
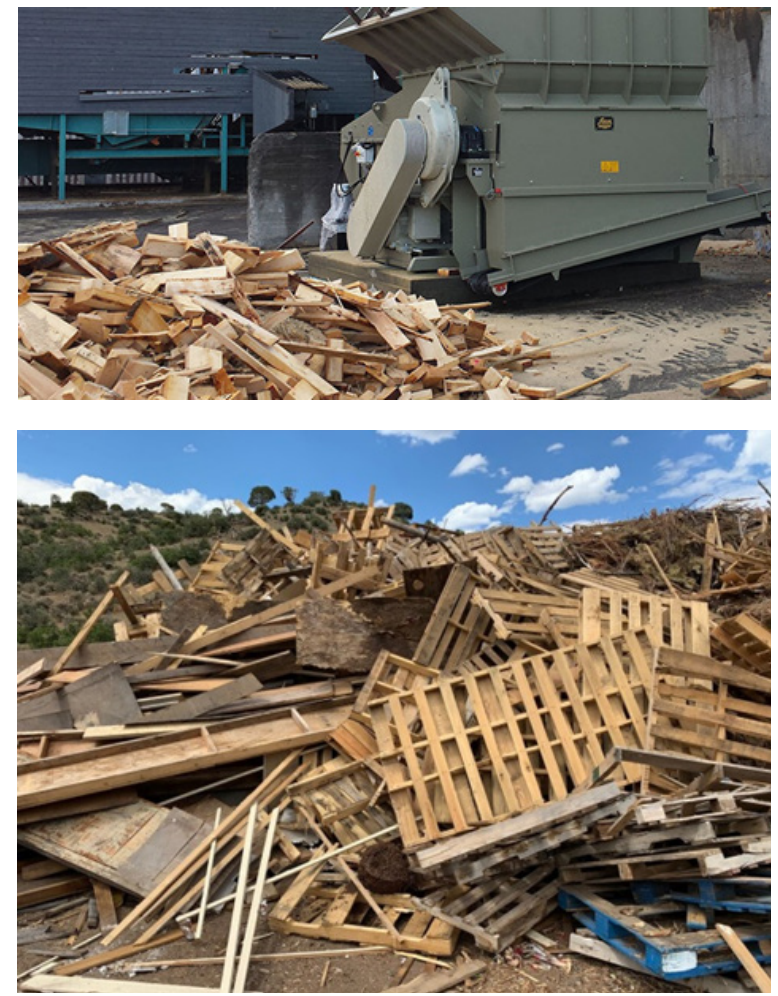

Fig. ( 4 ) Wood Waste: particleboards, medium density fiberboards (MDF), ply-wood, oriented strand boards

(OSB), and other wood composites

Wooden pieces never go out of style with their classic elegance, practicality and multi-varied textures and hues, from whites to gold's to reds to deep browns or dark blacks.. (14)

\section{3-1-1-waste wood in Egypt:}

Over recent years, more and more people have been buying environmentally friendly products for their homes, like cement tiles instead of ceramic, and furniture made of recycled materials like tables made out of old wooden doors or chairs made from agricultural waste like palm tree fibers or rice husks that would otherwise be burnt on farms.

In addition, some factories are now reusing waste of marble to make eco-friendly tiles that can be used in gardens or as aggregates in construction. This is an example of what is called "green business" in which a company aims to achieve a minimal negative impact on the environment.

According to government statistics, the sectors now going green in Egypt represent $60 \%$ of the real economy. To inspire more of these sectors to go green, the 
government has also launched its Pollution Reduction Program.

Mariam Korachy, also an architect, comments on the use of reused materials inside and outside homes. "Reused materials from old houses can be used for a variety of things like the wood of an old floor that could be used for a ceiling of a new house or as parquet flooring or to make furniture since wood is multi-purpose," she said. "It depends on what the owner of the house wants to do with it and how creative he is," she added, saying that such reclaimed wood can be used for fences, tables, or even a whole kitchen.

"Recycling includes a wide range of activities such as reusing objects or reshaping them or making the rubble of old houses into cement for building new ones," Korachy said, adding that experiments are also underway to get rid of debris more efficiently and in a more environmentally friendly way.

"Reused wood in Egypt is used by many people outdoors. However, I think that it is okay to use it indoors as well," she added.(6)

\section{3-2-Furniture industry:}

Especially furniture has become a fashion product with continuously declining life cycles.

The furniture industry encompasses manufacturers of both metal and wood furniture. Within the wood furniture manufacturing sector, three industries were identified as responsible for the majority of environmental releases:

Wood Household Furniture - Except Upholstered; Wood Household Furniture - Upholstered; and Wood Office Furniture. These industries typically include processes that shape, gather and finish wood into different types of furniture.

The four general processes of any wood furniture manufacturing operation are raw stock shaping, parts get-together, finishing or coatings application, and unit packaging. (3)

Wood furniture operations emit pollutants such as hazardous air pollutants (HAPs) and volatile organic compounds (VOC). These pollutants can donate to health problems that may affect shop employees, their families, customers, and the community. While Federal, state, local, and Tribal regulations limit the amount of emissions from wood furniture operations, dangerous releases of HAPs can occur if a wood fur- niture operations facility does not operate in compliance with regulations. (15)

\section{3-3-wood waste management:}

Successful wood waste management practices and strategies are developed to reduce environmental impacts, save costs, and to provide new chances.

In reality, the majority of waste wood that gets recycled is cut and the chips used to make chipboard or burnt in power stations. This involves the waste wood being industrially processed and shipped long distances, often overseas - so although using the wood in this way is preferable to landfill; it still has a significant carbon footprint. Much waste wood however is perfectly reusable; it's high-quality wood or wood products that shouldn't be "down cycled" into woodchip, but it's not cost-effective to resell using conventional methods. (16)
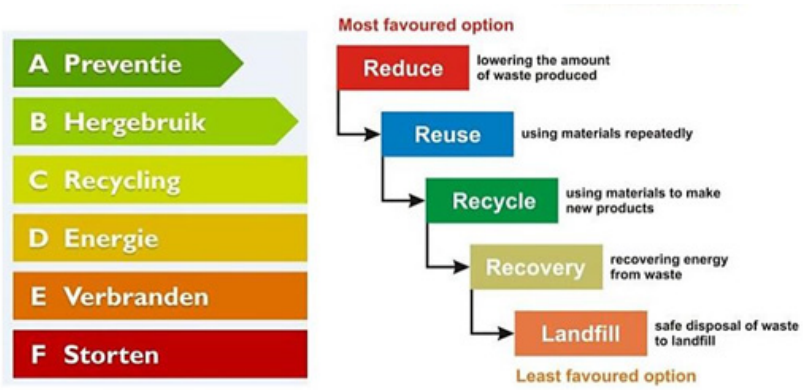

Fig. (5) The Waste Hierarchy

On the other hand, the recovery and reuse of wood are rapidly growing in popularity, albeit a tiny niche in terms of overall volume. Recovered wood is increasingly desirable by architects and homeowners. Unlike other recycled materials, recovered lumber often sells at a premium to new material, due to the labor involved in deconstruction and further processing to remove old nails or to re-machine. (17)

\section{3-4-Reuse vs. Recycling of wood waste :}

Nearly all types of solid wood can be reused. Wood can be recovered from old buildings, bridges and docks and used again in modern décor, from furniture to flooring. Smaller, less valuable wood leftovers can be collected and used to make particleboard and other composite products.

That's where our research aims to wildly apply reusing for waste wood instead of recycling it which increase the benefits of waste wood presented from 
wood industry .which may be pointed in:

1- Reduces landfill radiations. By finding a niche for reusable wood, we widen the waste wood end market, reducing wood sent to landfill. Methane is 25 times more damaging to the environment than carbon dioxide, and each tonne of wood which rots in landfill is thought to produce a quantity of methane as harmful as $600 \mathrm{~kg}$ of $\mathrm{CO} 2$.

2- Less energy wasted. Getting wood from normal forestry sources is thought to consume around 10 times more energy than it takes to prepare wood for reuse, making reused wood highly preferable for those wishing to reduce the environmental impact of their operations. It's also much more energy-efficient to reuse wood than recycling it by converting it into chipboard.

3- Ready community wood source. By providing a wide range of sustainable, locally-sourced wood and wooden products, we encourage communities to come together in making the best use of this great material. Because it absorbs carbon as it grows, about 1.6 tons of $\mathrm{CO} 2$ is taken out of the atmosphere for each tone of wood grown, as opposed to materials like metal which add up to 5 tons of $\mathrm{CO} 2$ to the atmosphere for each tone manufactured, in addition to the ground pollution caused by withdrawal. (16)
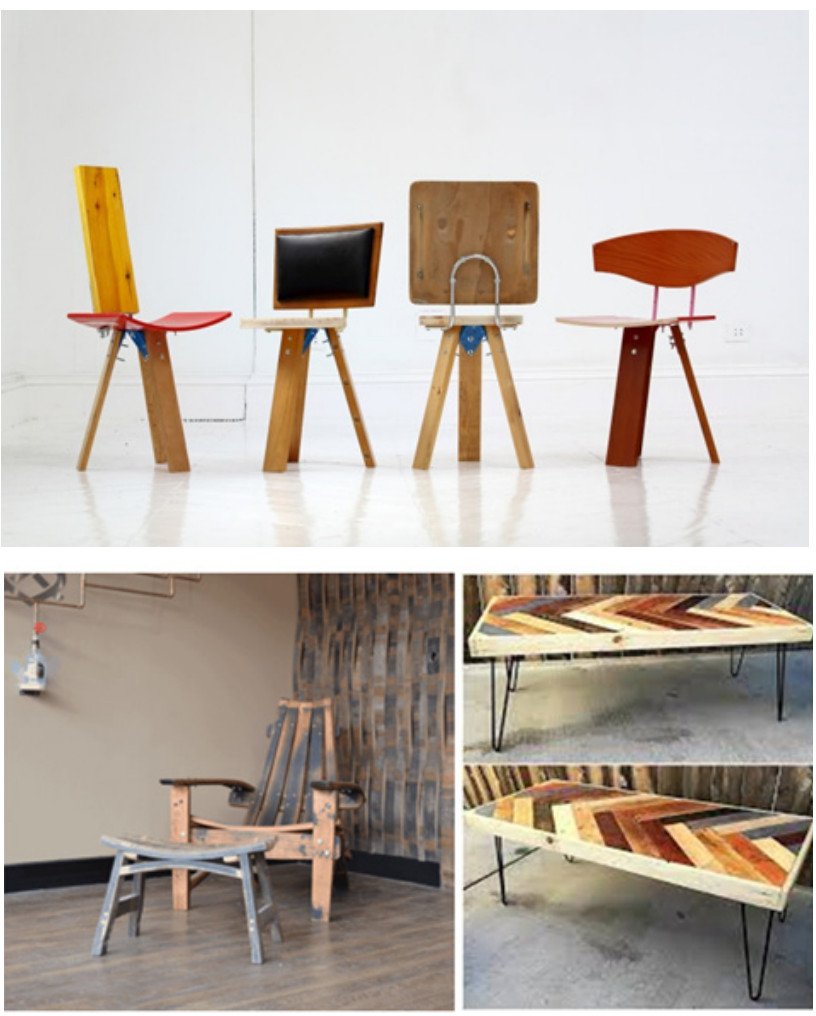

Fig. (6) Some examples of reuse wood in creative furniture (18)
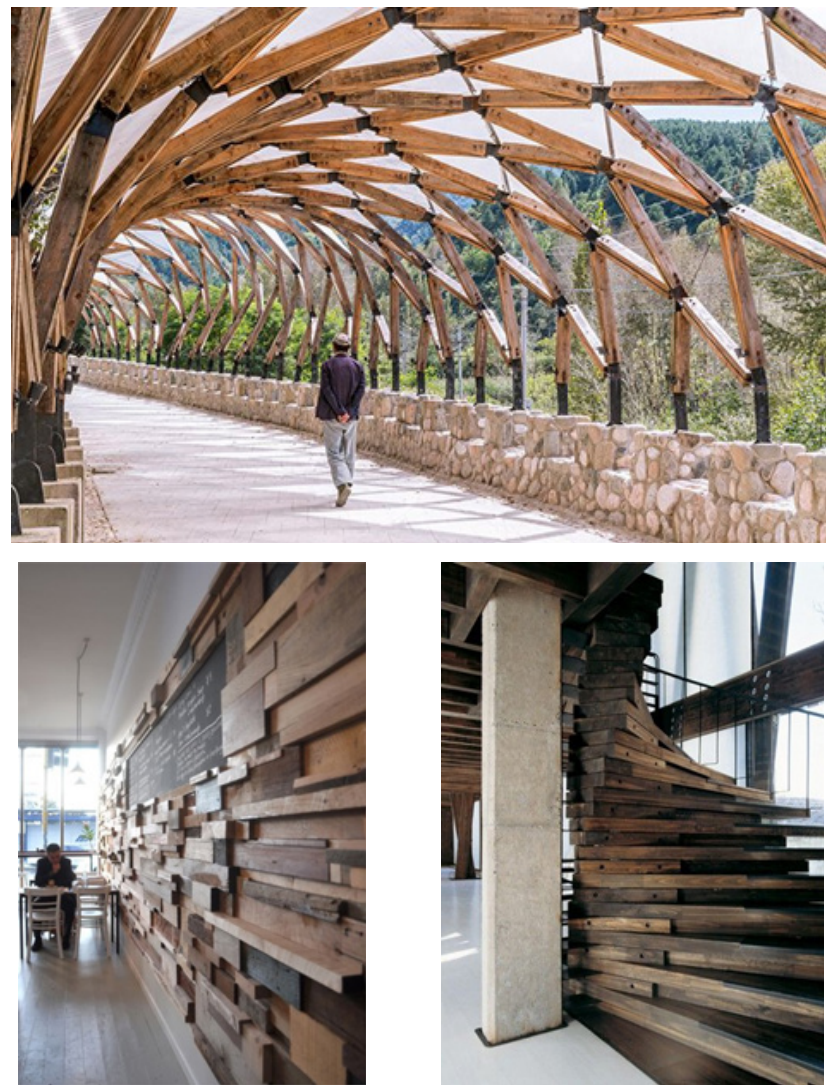

Fig. (7) Example for reusing wood waste in exterior \& interior design

\section{4-The proposed design:}

Designing a storage furniture unit with dimensions (L: $140 \mathrm{~cm}, \mathrm{H}: 60 \mathrm{~cm}, \mathrm{~W}: 38 \mathrm{~cm})$

\section{1- Design philosophy:}

The proposed design ( Fig. 8,9,10) depends on the reuse of wood waste produced from carpentry processes and work in companies and workshops in order to benefit from it in manufacturing furniture units with less cost. Moreover, it helps in eliminating the idea of income waste which helps in saving the materials as well as decreasing the pollution caused from using these wastes in forming synthetic wood panels.

\section{2- principles of the proposed design:}

1- Designing a furniture unit with an elegant functional perspective

2- Designing a furniture unit with a function of saving materials due to the usage of the natural materials to manufacture it resulting in no production of any emissions that can harm human health

3- Due to the method of manufacturing and the usage of natural materials in synthesis, the furniture unit is characterized by a long lifespan

4- Rationalize consumption of the materials as the furniture unit can be disassembled into the original materials and reusing them in a new manufacturing cycle. 

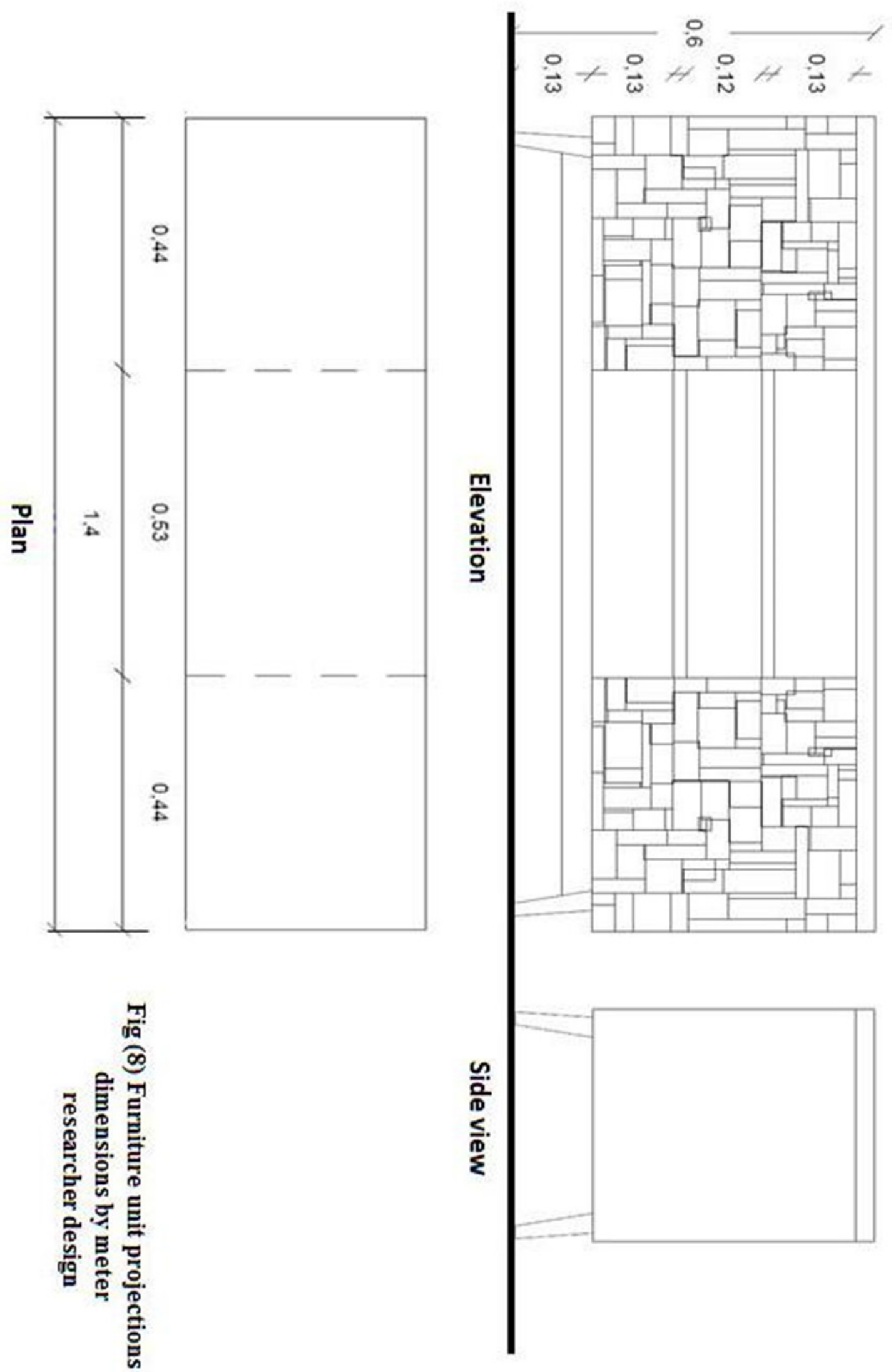


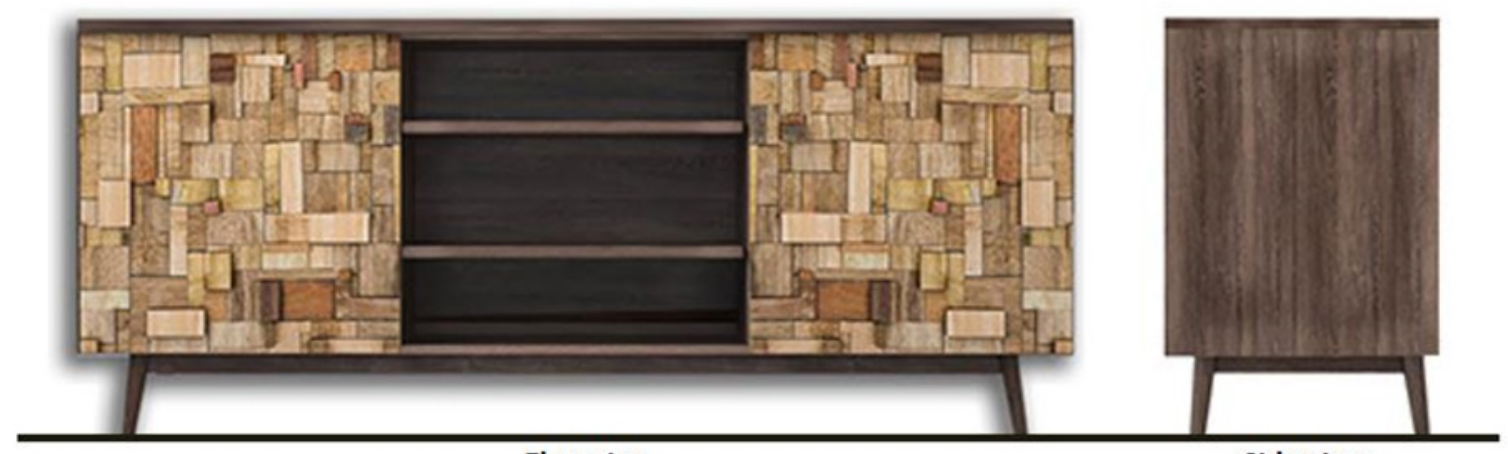

Elevation

Side view

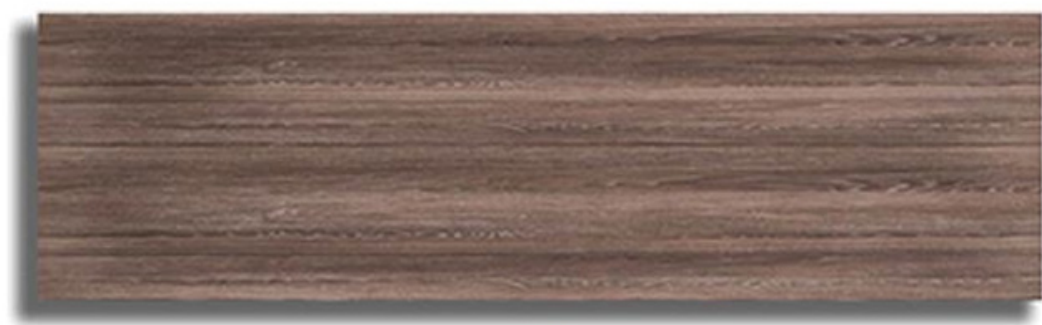

Plan

Fig. (9) Contemporary furniture unit design from wood waste according to reuse concept - researcher design

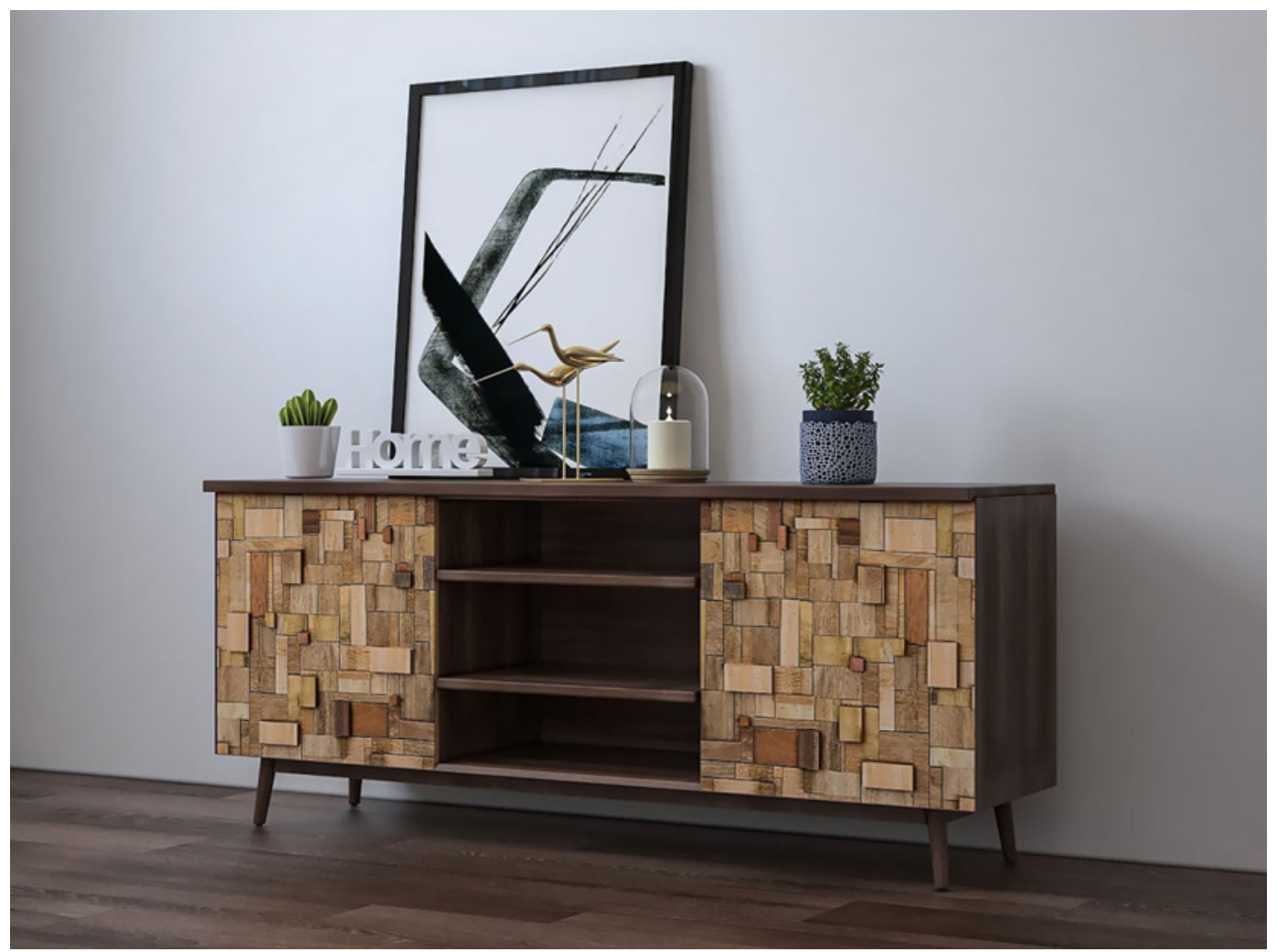

Fig. (10) Perspective clarifys the design idea for furniture unit - researcher design to reuse concept - researcher design 


\section{5- Results and recommendations:}

1. Recycling of wood waste from carpentry operations and using it in contemporary designs.

2. Rationalizing using and reusing of the material lies in the suitable design and appropriate of the capabilities of that material.

3. The design that can be disassembled and installed based on the reuse of single parts and their entry into a new reuse cycle after the end of the life of the furniture unit, is considered the most successful design in employing and adapting waste material.

4. Exploitation of wasted raw materials in new industries helps and stimulates the preservation of natural resources, which reflects positively on the preservation of environmental resources.

5. Reusing and recycling processes helped in increasing of workers in factories and workshops, resulting in decreasing unemployment ratio.

\section{6-References:}

1. Wagida A. Anwar, 'Environmental health in Egypt", International Journal of Hygiene and Environmental Health ,Volume 206, Issues 4-5, El SEVIER, (August 2003) ., Pages 339-350

2. https://www.communitywoodrecycling.org.uk/ learn-more/recycling-vs-reuse/.

3. David A. Hindin William M. Burch Special Projects Office and Daniel L. Fort , ( 1992 ) pp.1-26 .

4. Pollution Options in Wood Furniture Manufacturing A bibliographic Report (February 1992 ) . http://www.wrap.org.uk/about-us/about/ wrap-and-circular-economy .

5. https://www.europarl.europa.eu/news/en/headlines/economy/20151201STO05603/circular-economy-definition-importance-and-benefits

6. WWW.CSREGYPT.COM

7. https://www.egypttoday.com/Article/3/97230/ Cabinet-Egypt-s-Circular-economy-is-promising

8. https://en.wikipedia.org/wiki/Sustainable design\#Sustainable_Interior_Design

9. Rachel Emas - The Concept of Sustainable Development: Definition and Defining Principles Research gate - (January 2015 )

10. https://archive.epa.gov/airquality/community/ $\mathrm{web} / \mathrm{html} /$ woodfurniture_addl_info.html

11. Cynthia Bowman, The Ultimate Guide to Sustainable Furniture, October 6, (2020).

12. Jennie Morton, Sustainable Furniture Specification Guide-Building, April 27, (2012).
13. Susan Bolton, Ecological Engineering ; design Principles (2019)

14. Rick Leblanc - The Importance of Wood Recycling in C\&D Managemen- Updated November 26,( 2018 ).

15. Jyoti Jennings Roth - Reclaimed Wood Reused in 10 Wonderful Ways, December 29,( 2017)

16. Ursula Kües - Wood production, wood technology, and biotechnological impacts ( Recycling of Wood Composites and Solid Wood Products ) (January 2007) (pp.509-533) .

17. Maderas, Cienc. tecnol. vol.20 no.4 Concepción (Oct. 2018)

18. Rafael da Rosa Azambuja1 Vinicius Gomes de Castro2 Rosilani Trianoski3 Setsuo Iwakir - Recycling wood waste from construction and demolition to produce particleboards ( 2018 ). 